\title{
Pragmatic Approach toward Catalytic CO Emission Mitigation in Fluid Catalytic Cracking (FCC) Units
}

\author{
Aleksei Vjunov*, Karl C. Kharas, Vasileios Komvokis, Amy Dundee, Claire C. Zhang (D) and Bilge Yilmaz *(D) \\ BASF Corporation, 25 Middlesex/Essex Turnpike, Iselin, NJ 08830, USA; karl.kharas@basf.com (K.C.K.); \\ vasileios.komvokis@basf.com (V.K.); amy.dundee@basf.com (A.D.); claire.c.zhang@basf.com (C.C.Z.) \\ * Correspondence: aleksei.vjunov@basf.com (A.V.); bilge.yilmaz@basf.com (B.Y.); \\ Tel.: +1-732-331-5203 (A.V.); +1-646-413-9090 (B.Y.)
}

check for

updates

Citation: Vjunov, A.; Kharas, K.C.; Komvokis, V.; Dundee, A.; Zhang, C.C.; Yilmaz, B. Pragmatic Approach toward Catalytic CO Emission Mitigation in Fluid Catalytic Cracking (FCC) Units. Catalysts 2021, 11, 707. https://doi.org/10.3390/catal11060707

Academic Editors: José

Ignacio Lombraña, Héctor Valdés and Cristian Ferreiro

Received: 16 May 2021

Accepted: 1 June 2021

Published: 3 June 2021

Publisher's Note: MDPI stays neutral with regard to jurisdictional claims in published maps and institutional affiliations.

Copyright: (c) 2021 by the authors. Licensee MDPI, Basel, Switzerland. This article is an open access article distributed under the terms and conditions of the Creative Commons Attribution (CC BY) license (https:// creativecommons.org/licenses/by/ $4.0 /)$.
Abstract: The need to mitigate the environmental footprints of refineries in a sustainable and economical way is widely accepted, yet there appears to be a lack of a unilateral pragmatic approach towards $\mathrm{CO}$ oxidation to $\mathrm{CO}_{2}$ among the refining community. In this work we share $\mathrm{CO}$ promoter design strategies that can afford a tangible and immediate $\mathrm{CO}$ conversion efficiency increase without a need for additional precious metal loading. The key focus is on the support material architecture that is essential to boost the $\mathrm{CO}$ conversion and reduce the $\mathrm{NO}_{x}$ generation in the FCC unit. It was demonstrated that the suppression of Pt sintering as well as the enhancement of the oxygen mobility on the catalyst surface can afford an $\sim 40 \%$ lower cost of Pt and $\sim 20 \%$ lower usage rate compared to current industry-standard designs.

Keywords: Pt-based promoter; CO oxidation; environmental catalysis; refinery compliance; fluid catalytic cracking; FCC

\section{Introduction}

The ever-more stringent environmental regulations on air pollution, especially that caused by the oil refining industry, are drawing more efforts by refineries to combat these harmful emissions [1]. Some examples of the emissions of concern are $\mathrm{CO}, \mathrm{NO}_{x}, \mathrm{HCN}$, and $\mathrm{SO}_{x}$, to name a few-all of which can cause substantial harm to the environment, and human and animal health.

In this work, we focus on the $\mathrm{CO}$ and $\mathrm{NO}_{x}$ emissions as these are common and critical concerns during FCC catalyst regeneration as part of oil cracking. Moreover, the mitigation of such pollutants is now part of most oil refiners' commitment to sustainability [2]. The regenerator and related catalyst logistics are schematically presented in Figure 1. Specifically, incomplete coke combustion in the FCC unit regenerator may lead to $\mathrm{CO}$ and $\mathrm{O}_{2}$ breakthrough into the dilute phase $[3,4]$. The resulting combustion of $\mathrm{CO}$ in the dilute phase, referred to as afterburn, can produce high temperatures, which can damage regenerator internal hardware, and, therefore, cause an FCC unit outage [5]. While seemingly minor, such a sequence of events would cause a major disruption in a refinery operation and would also lead to substantial financial loss. Even without an outage, concerns around afterburn would lead refiners to run their FCC units at suboptimal conditions, hindering them from reaching full potential of their process and catalyst. 


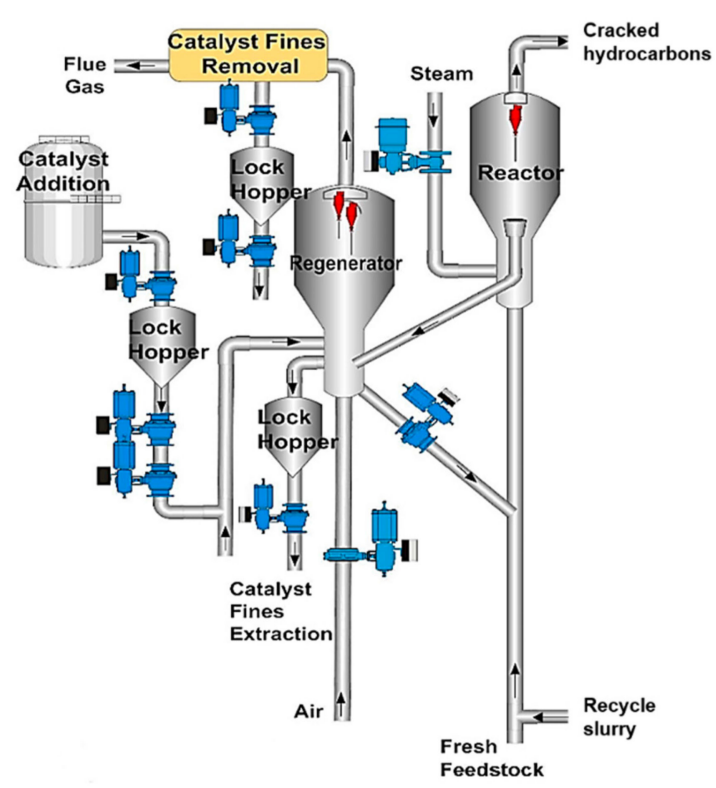

Figure 1. The FCC unit regenerator as well as the associated catalyst logistic streams are schematically shown.

To mitigate $\mathrm{CO}$ emissions, refineries typically use $\mathrm{CO}$ promoters that catalyze $\mathrm{CO}$ oxidation to $\mathrm{CO}_{2}$ in the dense bed. An additional benefit for $\mathrm{CO}$ promoters is improved air utilization. A CO promoter can typically be introduced as part of the FCC catalyst formulation or as a standalone additive. The CO promoter is usually based on highly dispersed supported platinum or palladium that can catalyze the oxidation reaction. The choice of metal is driven by a combination of regulatory certification, current emissions as well as budget for a given FCC unit operation. Typical CO promoter addition rates are 2-5 pounds of additive per short ton fresh FCC catalyst, which often corresponds to $\sim 1-3 \mathrm{ppm}$ platinum group metal (PGM) level in the circulating catalyst inventory [6].

Over the past years there have been numerous contributions to the field of $\mathrm{CO}$ oxidation chemistry. These include extensive and fundamental studies using advanced techniques, many summarized in recent review articles $[7,8]$. In this contribution, however, we focus predominantly on the $\mathrm{CO}$ promoter designs relevant to the refining industry with a focus on actual real-life industrial performance rather than fundamental mechanistic insights as to the nature of the occurring chemistry. Pt has been selected as the PGM of choice for this set of experiments. We aim to share the conceptual approach to pragmatic Pt-based CO promoter design as well as the underlying considerations and concepts that are economically viable and can find applications in actual FCC units worldwide.

\section{Experimental}

\subsection{Material Synthesis}

A series of reference and experimental catalysts was prepared, the full list is provided in Table 1. In all cases, $\gamma-\mathrm{Al}_{2} \mathrm{O}_{3}$ microspheres with a typical $\mathrm{D}_{50}$ of $80 \mu \mathrm{m}$ and a total surface area (TSA) of $90 \mathrm{~m}^{2} / \mathrm{g}$ were used as the alumina support. Commercially available cerium nitrate and strontium nitrate, industrial grade in all cases, were used as precursors to form the doping package for the alumina support. An aqueous solution of Pt-nitrate, with a typical Pt content of $10 \mathrm{wt} \%$ was used as the PGM source. Both dopants as well as PGM were deposited via incipient wetness impregnation to afford even metal distribution on the support. 
Table 1. The sample composition as well as measured $\mathrm{CO}$ conversion and $\mathrm{NO}_{x}$ generation values for the catalysts discussed in this contribution are reported.

\begin{tabular}{|c|c|c|c|c|c|c|}
\hline Promoter & $\mathrm{CeO}_{2}(\mathrm{wt} \%)$ & SrO (wt \%) & $\mathrm{Al}_{2} \mathrm{O}_{3}(\mathrm{wt} \%)$ & Pt (ppm) & $\begin{array}{c}\text { CO Conversion } \\
(\%)^{1}\end{array}$ & $\begin{array}{c}\text { NO }_{x} \text { Generation } \\
(\%)^{1}\end{array}$ \\
\hline Reference-1 & 0 & 0 & 99.97 & 300 & $47.6 \pm 2.4$ & $127.3 \pm 6.4$ \\
\hline Reference-2 & 0 & 0 & 99.95 & 500 & $43.8 \pm 2.2$ & $128 \pm 6.4$ \\
\hline Reference-3 & 0 & 0 & 99.92 & 800 & $47.6 \pm 2.4$ & $129 \pm 6.5$ \\
\hline Catalyst A & 3 & 0 & 96.97 & 300 & $54.4 \pm 2.7$ & $117.4 \pm 5.9$ \\
\hline Catalyst B & 6 & 0 & 93.97 & 300 & $57.5 \pm 2.9$ & $115.8 \pm 5.8$ \\
\hline Catalyst C & 10 & 0 & 89.97 & 300 & $62.1 \pm 3.1$ & $112.3 \pm 5.6$ \\
\hline Catalyst D & 18 & 0 & 81.97 & 300 & $64.2 \pm 3.2$ & $113.9 \pm 5.7$ \\
\hline Catalyst E & 10 & 2.6 & 87.37 & 300 & $64.1 \pm 3.2$ & $104.7 \pm 5.2$ \\
\hline Catalyst F & 10 & 4.7 & 85.27 & 300 & $67.0 \pm 3.4$ & $93.0 \pm 4.7$ \\
\hline
\end{tabular}

Reference catalysts 1-3 were prepared by impregnating the alumina support with the aqueous platinum nitrate solution such that the desired final metal concentration was achieved. Experimental Catalysts A-D were prepared by first impregnating the alumina support with cerium-nitrate such that the desired final $\mathrm{CeO}_{2}$ concentration was achieved. The support was then calcined at $550{ }^{\circ} \mathrm{C}$ for $2 \mathrm{~h}$. Subsequently, the desired amount of the $\mathrm{Pt}$ nitrate solution was impregnated onto the ceria/alumina support. Catalysts E-F were prepared by first impregnating the alumina support with an aqueous mixture of cerium- and strontium-nitrates such that the desired final $\mathrm{CeO}_{2}$ and $\mathrm{SrO}$ concentrations were achieved. The support was then calcined at $550{ }^{\circ} \mathrm{C}$ for $2 \mathrm{~h}$. Subsequently, the desired amount of the Pt nitrate solution was impregnated onto the ceria/strontia/alumina support. For all presented catalysts, upon Pt deposition, all samples were calcined at $550{ }^{\circ} \mathrm{C}$ for $2 \mathrm{~h}$.

\subsection{Catalyst Characterization}

All catalysts were characterized after synthesis. The surface area measurements were performed using Micromeritics TriStar models 3030/3020. The surface area in all cases was quite similar with the $\mathrm{Pt} / \mathrm{Al}_{2} \mathrm{O}_{3}$ samples having a typical TSA of $90 \mathrm{~m}^{2} / \mathrm{g}$, $\mathrm{Pt} / \mathrm{CeO}_{2} / \mathrm{Al}_{2} \mathrm{O}_{3}$ as well as the $\mathrm{Pt} / \mathrm{SrO} / \mathrm{CeO}_{2} / \mathrm{Al}_{2} \mathrm{O}_{3}$ catalysts having a typical TSA of $80-85 \mathrm{~m}^{2} / \mathrm{g}$. The catalyst composition was determined using the Inductively Coupled Plasma (ICP) test on a Thermo iCAP 7400. The compositions of each presented catalyst are summarized in Table 1.

\subsection{Catalyst Testing}

Catalysts were tested as-is, also referred to as "fresh" state, as well as after a simulated aging, referred to as "aged". The aging conditions as well as details of the experimental setup are reported in the description of the specific experiment in the results section. The absolute conversion levels were measured at the Chemical Process and Energy Resources Institute (CPERI) located in Thessaloniki, Greece. A spent FCC catalyst was used for the base case tests, while for the evaluation studies mixtures of $1 \mathrm{wt} \%$ of the additive and 99 $\mathrm{wt} \%$ of the spent catalyst were loaded on the reactor. All presented data is reported as the difference compared to the promoter-free base emission. Prior to testing, all catalytic materials were sieved to 63-106 $\mu \mathrm{m}$. The accuracy of the reported $\mathrm{CO}$ and $\mathrm{NO}_{x}$ emissions values was determined by performing a statically relevant number of repetitions. For the chosen reactor setup and under the specific experimental conditions reported in this study, 
an average variation of $\pm 5 \%$ was determined. The reaction conditions for the chosen test protocol are reported in Table 2.

Table 2. The CO promoter testing parameters are reported.

\begin{tabular}{cc}
\hline Reactor Type & Fluid Bed \\
\hline Reactor loading & $10 \mathrm{gr}$ \\
\hline Catalyst mixture & $99 \mathrm{wt} \%$ spent $\mathrm{FCC}$ catalyst $+1 \mathrm{wt} \%$ CO promoter \\
\hline Inlet gas flow rate & $1 \mathrm{~L} / \mathrm{min}$ \\
\hline Inlet gas composition & $2 \mathrm{vol} \% \mathrm{O}_{2}$ in $\mathrm{N}_{2}$ \\
\hline Reactor bed temperature & $700{ }^{\circ} \mathrm{C}$ \\
\hline
\end{tabular}

The $\mathrm{CO}$ conversion (\%) as well as $\mathrm{NO}_{x}$ generation (\%) values were calculated using the formula reported in Equation (1).

$$
\mathrm{CO} \text { or } \mathrm{NO}_{x}(\%)=100 \times \frac{\left(\mathrm{CO} \text { or } \mathrm{NO}_{x}\right)_{\text {Base Case }}-\left(\mathrm{CO} \text { or } \mathrm{NO}_{x}\right)_{\text {Promoter }}}{\left(\mathrm{CO} \text { or } \mathrm{NO}_{x}\right)_{\text {Base Case }}}
$$

Equation (1). The formula used to determine the $\mathrm{CO}$ conversion (\%) as well as $\mathrm{NO}_{x}$ generation $(\%)$ values is reported.

\section{Results and Discussion}

\subsection{Promoter Pt-Loading}

The impact of Pt-loading on the activity of a typical CO promoter is demonstrated using the example of the reference catalysts $1-3\left(\mathrm{Pt} / \mathrm{Al}_{2} \mathrm{O}_{3}\right)$ with different Pt-loadings (see Table 1). Overall, there appears to be essentially no difference between the three chosen Pt-loadings when the overall catalyst design is identical. At first, this result may be somewhat surprising as this observation would suggest that a large fraction of the precious metal is apparently not contributing to the catalytic activity. However, the observation may relate to the chosen synthetic pathway and the resulting relative size of the Pt-clusters on the support surface. From prior reports on spectroscopic studies of precious metal catalysts $[9,10]$, in a $1 \mathrm{~nm} \mathrm{Pt}$ particle the ratio of surface $\mathrm{Pt}$ to $\mathrm{Pt}$ forming the core of the particle is $\sim 1: 1$. With growing particle size, the average Pt coordination number will grow and, as a result, in a $20 \mathrm{~nm} \mathrm{Pt}$ particle the surface Pt atoms account for approximately $5 \%$ of the total metal forming the said particle. Considering the particle size for a typical industrial catalyst, such as those presented here, increasing Pt loading on the support further leads to ever-diminishing returns as the available Pt surface area is essentially unchanged as the diameter of the Pt clusters is increased. Therefore, while some refineries may choose to increase the precious metal levels to combat growing $\mathrm{CO}$ emissions, the benefit of such an approach is limited and inherently inefficient.

An example of this is demonstrated using reference catalysts 1-3, which differ only in the amount of Pt deposited onto the support. From Figure 2, within the experimental uncertainty, the efficiency for $\mathrm{CO}$ conversion as well as $\mathrm{NO}_{x}$ generation in the fresh state is similar in all cases. The key difference is in the actual cost to the refiner $(\$ / \mathrm{mT})$ of $\mathrm{Pt}$ used, which ranges from $\sim 8700 \$ / \mathrm{mT}$ to $\sim 23000 \$ / \mathrm{mT}$ (at $900 \$ / \mathrm{oz}$ t Pt market price, a reasonable average value in the 2016-2020 timeframe) [11]. Note that the financial impact increases with the growing (USD $1200 / \mathrm{oz} t$ ) Pt market price, as has been experienced in late 2020 and early 2021 [11]. 


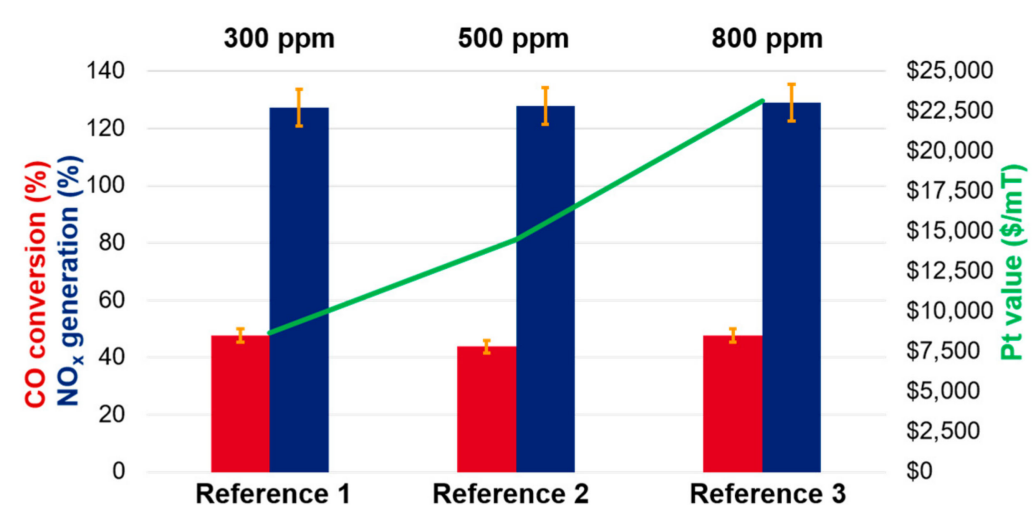

Figure 2. The $\mathrm{CO}$ conversion and $\mathrm{NO}_{x}$ generation observed for reference catalysts with varying $\mathrm{Pt}$ loadings are reported. The respective value of $\mathrm{Pt}(\$ / \mathrm{mT})$ at a 2016-2020 average market price of 900 $\$ / \mathrm{oz}$ t Pt [11] is also reported for reference.

Therefore, while a refinery may be under the impression that superior performance is obtained through a higher amount of metal, the actual value proposition diminishes substantially with increasing Pt loading. That is, on a relative basis, when the support material is identical in all cases, the oxidation of a $\mathrm{CO}$ molecule to $\mathrm{CO}_{2}$ is $~ 2.6$-times more cost-effective with reference- 1 than with reference- 3 , when the value of the $\mathrm{Pt}$ is considered. These considerations, of course, are true when the total concentration of the $\mathrm{CO}$ promoter component in an FCC blend is constant and only the PGM amount allocated on this component is increased. An alternative scenario would be for a refinery to increase the total $\mathrm{Pt}$ content by increasing the amount of $\mathrm{CO}$ promoter in the blend. For example, instead of using $0.25 \mathrm{wt} \%$ CO promoter with $1000 \mathrm{ppm} \mathrm{Pt}$, the FCC blend could be formulated using $0.5 \mathrm{wt} \% \mathrm{CO}$ promoter with $500 \mathrm{ppm}$ Pt. In this case, the benefit of increasing the total Pt in the FCC unit is more pronounced, and in certain cases may lead to the desired improvement of the apparent $\mathrm{CO}$ conversion. However, such an approach will typically also lead to a significant $\mathrm{NO}_{x}$ emission increase, a much undesired side-effect that in certain areas with very tight emissions regulations, e.g., California, would not be a viable solution. Beyond the $\mathrm{NO}_{x}$ concern, most of the precious metal in such an FCC blend would still remain inactive since it forms the core of the PGM-particles. Overall, such an approach could be considered a better of the two poor solutions. Indeed, there are many other, cost-efficient, means to consider before the Pt content is increased, as we will discuss in subsequent paragraphs.

We note at this point that the support used for the catalyst adds further, in some cases significant, costs to the overall Pt promoter design. As Pt loading has limited benefit, we hence focus on the maximization of Pt utilization through support tuning, which is a far more efficient and cost-effective way to reduce $\mathrm{CO}$ emissions when the total refinery spend on environmental compliance is considered.

\subsection{Promoter Doping}

To demonstrate the potential of catalyst support modification towards improved activity, we explore the impact of support doping. In this work, the impact of catalyst doping with ceria is demonstrated using the $300 \mathrm{ppm}$ Pt reference- 1 as well as a series of catalysts A-D composed of $300 \mathrm{ppm}$ Pt supported on alumina with different levels of $\mathrm{CeO}_{2}$ (see Table 1 for details). The reference CO promoter achieves a $47.6 \%$ conversion of $\mathrm{CO}$ to $\mathrm{CO}_{2}$ under chosen experimental conditions. This will be used as baseline for further assessment of the impact of ceria as an improvement of the $\mathrm{CO}$ conversion is observed with increasing amounts of ceria. These results are summarized in Figure 3. 


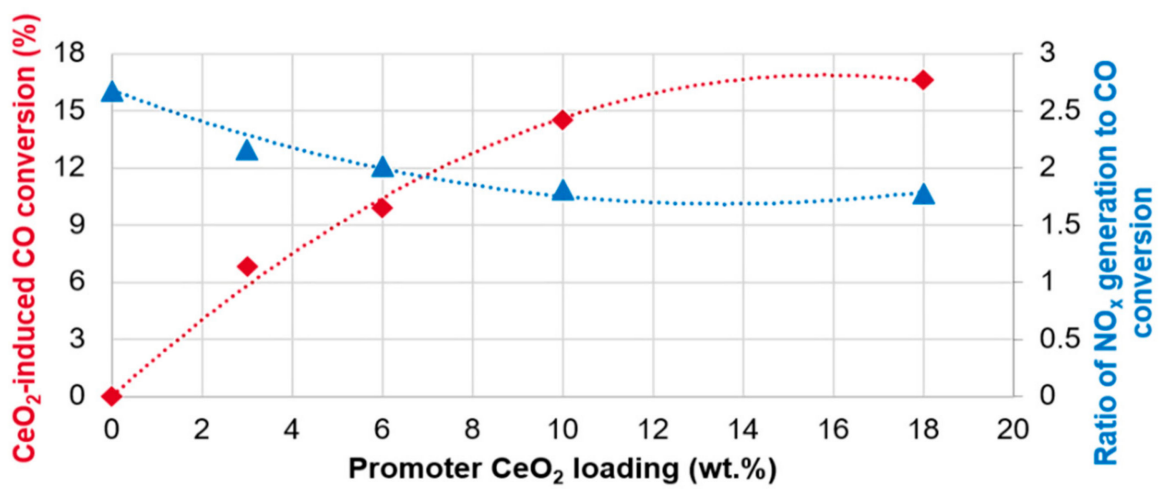

Figure 3. The $\mathrm{CeO}_{2}$-induced $\mathrm{CO}$ conversion as well as the ratio of $\mathrm{NO}_{x}$ generation to $\mathrm{CO}$ conversion are reported as a function of promoter $\mathrm{CeO}_{2}$ content. The lines are intended for trend visualization purposes only. Catalysts were tested by mixing $99 \%$ spent FCC catalyst and 1\% fresh promoter using a plug flow reactor operating at $1 \mathrm{~L} / \mathrm{min}$ flow rate with a feed of $2 \mathrm{vol} . \% \mathrm{O}_{2}$ in $\mathrm{N}_{2}$ at $700{ }^{\circ} \mathrm{C}$. The emissions values determined by comparing to a promoter-free base case experiment. The method used to calculate $\mathrm{CO}$ conversion and $\mathrm{NO}_{x}$ generation is reported in the experimental section. The color-coding is reported in the plot.

We observe a nearly linear $\mathrm{CO}$ conversion improvement between $0 \%$ and $~ 10 \% \mathrm{CeO}_{2}$ doping of the CO promoter. Beyond $\sim 10 \%$, the impact of ceria is greatly diminished with only minor improvement in ever-increasing $\mathrm{CeO}_{2}$ loading. There are at least two possible reasons why the addition of ceria is beneficial to the promoter performance when measured in fresh state. First, ceria itself is known as an oxidation catalyst $[12,13]$ that can convert $\mathrm{CO}$ to $\mathrm{CO}_{2}$ at elevated temperatures, either by itself or as a mixture with further oxides, e.g., $\mathrm{CuO}$ [14]. Second, the chosen aging and testing conditions may be quite favorable for the doped CO promoter. The testing temperature of $700{ }^{\circ} \mathrm{C}$, when the thermal stability of ceria is considered, is quite mild and does not affect the ability of ceria to serve as an oxygen storage component (OSC) [15]. The addition of OSC, whether in the form of ceria/zirconia or ceria by itself, to PGM is a well-known concept in the field of mobile emissions control [16] and has been shown to allow for optimized surface $\mathrm{O}_{2}$ concentration on the PGM surface, thus maximizing the metal efficacy for CO oxidation [17].

The diminishing benefit of increasing ceria content above $~ 10 \%$ is explained by several factors: (1) kinetic limitation of the reaction under chosen testing conditions and (2) the way the discussed promoters were prepared. As an example, the degree of the OSC capacity utilization is expected to decrease with increasing $\mathrm{CeO}_{2}$ content due to mass transfer limitations and the inaccessibility of a portion of ceria in the $\mathrm{CeO}_{2}$-particle core.

Another important observation for the presented sample set is that the addition of ceria leads to a decrease in $\mathrm{NO}_{x}$ generation by as much as $\sim 10 \%$ (Table 1 ). This feature is important as some refineries, especially those with a high Nelson complexity index (NCI), prefer to view the $\mathrm{CO}$ promoter performance as a ratio of $\mathrm{CO}$ conversion benefit balanced by the $\mathrm{NO}_{x}$ penalty. That is, one can assess promoter efficiency based on how much $\mathrm{NO}_{x}$ is generated per molecule $\mathrm{CO}$ that is oxidized. The ratio of $\mathrm{NO}_{x}$ generation to $\mathrm{CO}$ conversion for the studied sample-set is reported in Figure 3. Interestingly, while for every $1 \%$ of CO conversion the reference, ceria-free, promoter generates $\sim 2.7 \%$ additional $\mathrm{NO}_{x}$ emission, the addition of $10 \%$ ceria allows one to decrease the $\mathrm{NO}_{x}$ generation to $\sim 1.8 \%$ per $1 \% \mathrm{CO}$ conversion. Therefore, the addition of ceria has not only allowed boosting the absolute $\mathrm{CO}$ conversion levels, but also to decrease the relative $\mathrm{NO}_{x}$ emissions by as much as $\sim 33 \%$, a very significant value for most oil refineries. Again, it should be noted that, similar to $\mathrm{CO}$ conversion, the $\mathrm{NO}_{x}$ benefit becomes marginal beyond $\sim 10 \% \mathrm{CeO}_{2}$ content.

While there is a multitude of factors affecting the $\mathrm{NO}_{x}$ generation, there are at least two that we propose relevant to explain the observations in this work. Suggested causes are surmised and are the focus of an ongoing research project outside the frame of the current contribution. First, the addition of ceria is suggested to affect the rates of $\mathrm{CO}$ 
and NO oxidation shifting the balance in favor of $\mathrm{CO}$. Second, under chosen reaction conditions ceria can contribute to the apparently lower $\mathrm{NO}_{x}$ emissions by trapping a portion of the $\mathrm{NO}_{2}$, a product of $\mathrm{NO}$ oxidation, in the form of ceria-nitrate. Examples of $\mathrm{NO}_{x}$-traps using PGM/ceria components have been previously reported in the field of mobile emissions control $[18,19]$. Such a mechanism is suggested favorable for a CO promoter geared towards applications in the oil refining industry. As an example, the promoter can trap a portion of the generated $\mathrm{NO}_{x}$ in the regenerator. Subsequently, as the promoter circulates through the FCC unit, cerium nitrate can be regenerated in the riser to ceria while releasing $\mathrm{NO}_{x}$, which in turn can be converted to ammonia and thus removed at the top of the riser column. The regenerated ceria is then ready for the subsequent regenerator cycle. It is worth noting that while the effect is likely significant to help boost CO conversion, the typical amounts of promoter in the FCC catalyst blends (often around $1 \mathrm{wt} \%$ ) are generally insufficient to dramatically shift the refinery $\mathrm{NO}_{x}$ emission. Therefore, the proposed $\mathrm{NO}_{x}$ emissions reduction is generally considered less efficient than the installation of a stationary $\mathrm{NO}_{x}$-scrubber that operates via selective catalytic reduction (SCR) of $\mathrm{NO}_{x}$ with ammonia [20].

\section{3. $\mathrm{NO}_{x}$ Emission Suppression}

To supplement the $\mathrm{NO}_{x}$ observations discussed in the previous chapter, a series of experiments were performed using formulations that in addition to ceria also incorporated further $\mathrm{NO}_{\mathrm{x}}$-trapping components, similar to those typically reported for Lean $\mathrm{NO}_{x}$ Trap (LNT) diesel applications in mobile emissions control [21]. Two additional samples, catalyst $\mathrm{E}$ (catalyst $\mathrm{C}$ doped with $2.6 \% \mathrm{SrO}$ ) and catalyst $\mathrm{F}$ (catalyst $\mathrm{C}$ doped with $4.7 \% \mathrm{SrO}$ ), see Table 1, were prepared and compared in their $\mathrm{CO}$ conversion as well as $\mathrm{NO}_{x}$ generation activity to catalyst $C$, which is one of more active promoter designs discussed in present work. The $\mathrm{CO}$ conversion and $\mathrm{NO}_{x}$ generation values for these catalysts are reported in Table 1. Sr, specifically in the form of $\mathrm{SrO}$, has been widely proposed to manage $\mathrm{NO}_{x}$ emissions in the past and is hence a suitable example of such chemistry [22,23]. Further comparison of the impact of $\mathrm{SrO}$ on overall activity is shown in Figure 4.

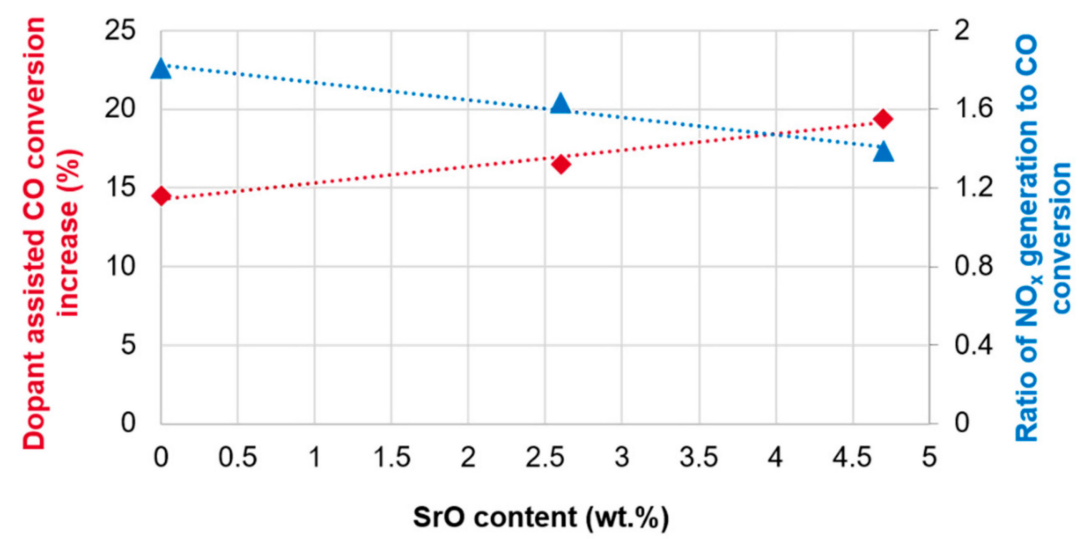

Figure 4. The dopant-assisted $\mathrm{CO}$ conversion as well as the ratio of $\mathrm{NO}_{x}$ generation to $\mathrm{CO}$ conversion are reported as a function of promoter $\mathrm{SrO}$ content. The color-coding is reported in the plot alongside with fitted curves exemplifying the discussed trends. Catalysts were tested by mixing $99 \%$ spent FCC catalyst and $1 \%$ fresh promoter using a plug flow reactor operating at $1 \mathrm{~L} / \mathrm{min}$ flow rate with a feed of $2 \mathrm{vol} . \% \mathrm{O}_{2}$ in $\mathrm{N}_{2}$ at $700{ }^{\circ} \mathrm{C}$. The emissions values determined by comparing to a promoter-free base case experiment. The method used to calculate $\mathrm{CO}$ conversion and $\mathrm{NO}_{x}$ generation is reported in the experimental section.

It should be noted that the addition of $\mathrm{SrO}$ to catalyst $\mathrm{C}$ leads to a near-linear improvement (Figure 4) in both $\mathrm{CO}$ conversion increase and $\mathrm{NO}_{x}$ generation reduction, which suggests these reactions are closely coupled. The observation is explained by the ability of SrO to trap $\mathrm{NO}_{2}$ in the form of strontium nitrate, which can then be decomposed in the 
riser to yield ammonia and the regenerated $\mathrm{SrO}$, much like the mechanism described for $\mathrm{CeO}_{2}$ in the previous chapter. The key difference here is that $\mathrm{SrO}$, due to its nature, cannot contribute to $\mathrm{CO}$ oxidation. In turn, this means that while $\mathrm{SrO}$ selectively stores $\mathrm{NO}_{2}$, a larger amount of the ceria remains available to oxidize CO rather than be "deactivated" by $\mathrm{NO}_{2}$ adsorption. This operation is very similar to that of a typical LNT design for diesel emissions system applications, where the $\mathrm{NO}_{x}$-trapping function is partially decoupled from $\mathrm{CO}$ and hydrocarbon oxidation to maximize catalytic efficiency [24].

With the potential $\mathrm{NO}_{x}$ emissions suppression in mind, it is not obvious that the addition of a dedicated $\mathrm{NO}_{x}$-trapping component is the most practical approach towards $\mathrm{NO}_{x}$ management in a refinery since the necessary amount of such SrO-based trap would need to comprise a substantial amount, e.g., $10-20 \%$, of the FCC formulation, which is not a viable approach towards $\mathrm{NO}_{x}$ mitigation in most existing FCC units.

\subsection{Impact of Aging}

Two catalysts are chosen for further testing to assess the impact of promoter aging on performance under conditions typical of an FCC unit. Specifically, two designs are compared here, these are reference-2, a $500 \mathrm{ppm} \mathrm{Pt}$ containing promoter that is similar to those designs often used in commercial applications, and catalyst C, $300 \mathrm{ppm} \mathrm{Pt}$ and $10 \%$ $\mathrm{CeO}_{2}$ containing promoter design that has shown optimal $\mathrm{NO}_{x} / \mathrm{CO}$ ratio, as discussed in previous chapter. Additional information on these two catalysts is provided in Table 1. It is important to note that while at first glance the comparison may not seem direct or fair, we focus on a real-life type of application, where a refinery would consider one or two catalysts at most when selecting the $\mathrm{CO}$ promoter for their application. Ultimately, what is most critical, is the highest efficiency per unit catalyst, i.e., lb or kg, rather than specific elemental composition, as this approach allows for a minimization of the monthly CO promoter spend at the refinery.

There are two types of aging tests that were developed for this workstream. First, a steam-aging, which is used to simulate the regenerator portion of the FCC operation cycle. Here, we chose a $12 \mathrm{~h}$ aging duration with a $\mathrm{T}_{\max }=787^{\circ} \mathrm{C}$ using a sealed steam reactor that is filled with a $90 \% \mathrm{H}_{2} \mathrm{O}$-steam $/ 10 \% \mathrm{~N}_{2}$ mixture. Second, Lean/Rich (L/R) aging, which is more typical for a mobile emissions control testing setup, e.g., for a very lean diesel engine, that mimics the full FCC unit operation cycle. This aging is also $12 \mathrm{~h}$ in duration, reaches a $\mathrm{T}_{\max }=780^{\circ} \mathrm{C}$ and is performed using a flow-through reactor that cycles with $10 \mathrm{~min}$ Air, followed by $10 \mathrm{~min} \mathrm{~N}_{2}$, followed by $10 \mathrm{~min} \mathrm{H}_{2}$, followed by $10 \mathrm{~min} \mathrm{~N}_{2}$, while at a constant $10 \% \mathrm{H}_{2} \mathrm{O}$-steam in every step. Due to powder bed penetration difference between air and $\mathrm{H}_{2}$, the 10 min $\mathrm{H}_{2}$ reduction is equivalent to $\sim 1$ min reduction using hydrocarbons. This point is important as it simulates the relative time a CO promoter spends in the FCC unit, i.e., $\sim 90 \%$ of the lifetime in the regenerator and $\sim 10 \%$ lifetime in the riser, where the promoter can be regenerated. The comparison of the said two samples in fresh as well as aged form is shown in Figure 5. 

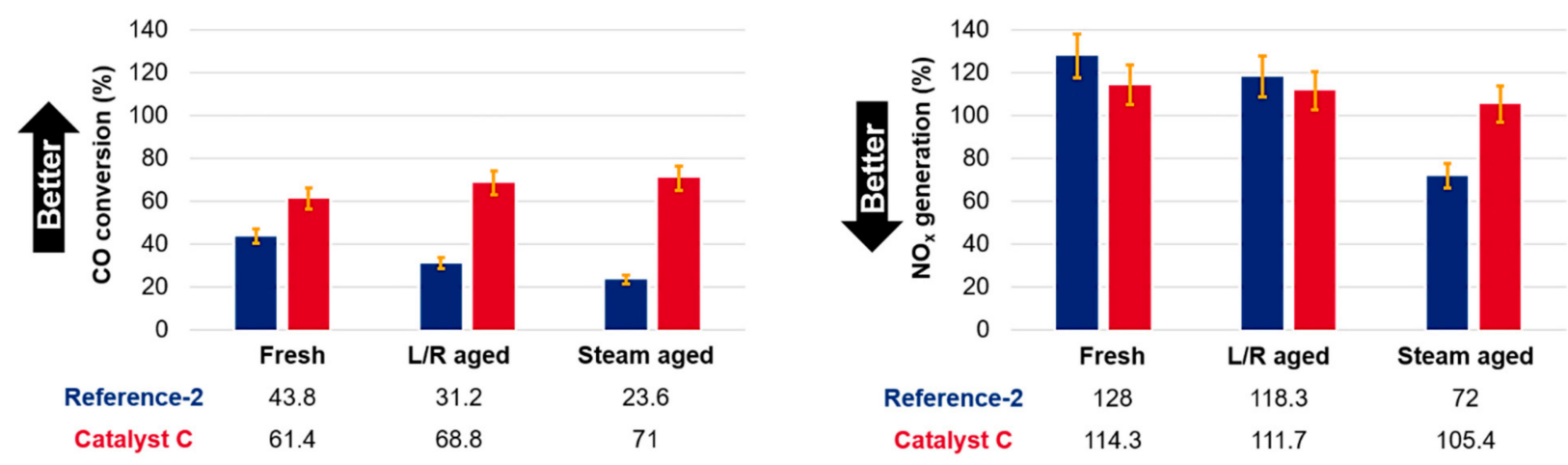

Figure 5. The activity of reference- 2 and catalyst $\mathrm{C}$ in fresh as well as aged form for $\mathrm{CO}$ conversion and $\mathrm{NO}_{x}$ generation are reported. The color-coding as well as the actual measured values are reported in the plots. Catalysts were tested by mixing $99 \%$ spent FCC catalyst and $1 \%$ fresh promoter using a plug flow reactor operating at $1 \mathrm{~L} / \mathrm{min}$ flow rate with a feed of 2 vol. $\% \mathrm{O}_{2}$ in $\mathrm{N}_{2}$ at $700{ }^{\circ} \mathrm{C}$. The emissions values determined by comparing to a promoter-free base case experiment. The method used to calculate $\mathrm{CO}$ conversion and $\mathrm{NO}_{x}$ generation is reported in the experimental section.

The superiority of catalyst $C$ to the reference-2, regardless of the lower Pt content in the experimental sample was expected based on fresh testing. However, the extent of the aging on the said catalysts was not obvious prior to testing. For $\mathrm{CO}$ conversion, the $\mathrm{CO}$ activity of the reference- 2 design is decreased by $25-50 \%$ depending on the aging type, with steam aging being particularly harmful.

At this point we believe it is necessary to provide a side note on the nature of Pt aging as often observed in mobile emissions control, e.g., for diesel-type emissions mitigation systems. Pt is quite mobile in the oxide form and stable in metallic form when it comes to sintering or Ostwald ripening $[25,26]$. What this translates to is an elevated degree of mobility on the surface that ultimately leads to a higher extent of agglomeration upon aging in the absence of reductants. Therefore, while both aging protocols in this work had a nominal duration of $12 \mathrm{~h}$, the actual time Pt was subject to oxidation was different, with more favorable conditions in the $\mathrm{L} / \mathrm{R}$ aging case. Since Pt was offered the occasional regeneration step, that in turn has led to an apparent higher degree of $\mathrm{CO}$ activity after the $12 \mathrm{~h} \mathrm{~L} / \mathrm{R}$ aging cycle compared to steam aging. The key learning here is that the promoter aging protocol must be chosen such to best suit the actual refinery operation. In turn, this approach not only allows the correct promoter dosing and durability estimate, but also a fair comparison of competing catalyst technologies (e.g., as part of catalyst vendor bids).

With the above in mind, the remarkable stability of catalyst $C$ after both aging protocols deserves a further explanation as the performance appears to improve slightly with aging. There are two key reasons for this observation. First, the $\mathrm{CeO}_{2}$ that is present in catalyst $\mathrm{C}$ will exhibit some $\mathrm{CO}$ activity on its own, as discussed previously. The aging conditions chosen in this work are generally below temperatures that are considered harmful to ceria, i.e., cause structural collapse and stop oxygen mobility [27]. Therefore, the $\mathrm{CeO}_{2}-$ contribution to $\mathrm{CO}$ oxidation is essentially unaffected. Second, likely even more prominent, ceria when introduced to the promoter design in an appropriate manner, can serve as an anchoring point for $\mathrm{Pt}$ as the affinity of $\mathrm{Pt}$ to $\mathrm{CeO}_{2}$ is known to exceed that of $\mathrm{Pt}$ to $\mathrm{Al}_{2} \mathrm{O}_{3}$ [28]. Therefore, as the aging begins, $\mathrm{Pt}$ that may be randomly distributed on the surface of the promoter particle, is quickly anchored on the surface of ceria domains. This in turn means that $\mathrm{Pt}$ is given little opportunity to find further Pt particles and sinter into larger Pt clusters on the promoter surface. The large number of small anchored $\mathrm{Pt}$ particles offers a significantly larger apparent $\mathrm{Pt}$ surface area that is available for the CO oxidation reaction. Additionally, ceria can stabilize $\mathrm{Pt}$ at atomic dispersion which is active for $\mathrm{CO}$ oxidation but not for dehydrogenation chemistry $[29,30]$. Finally, while it is not possible to completely exclude some degree of Pt encapsulation with ceria, the relatively mild aging temperatures [31], as compared to some of the most aggressive environmental catalysis type aging conditions [32], lead us to surmise that the anchoring of Pt with ceria 
has a significant net-benefit effect over a simpler $\mathrm{Pt} / \mathrm{Al}_{2} \mathrm{O}_{3}$ type design under operation conditions typical of a refinery FCC unit.

As for $\mathrm{NO}_{x}$ generation, the same general observations and explanations as those discussed for $\mathrm{CO}$ conversion are still valid. The decrease of the Pt surface area due to sintering leads to diminishing $\mathrm{NO}_{x}$ emissions. For Catalyst $\mathrm{C}$, the $\mathrm{NO}_{x}$ generation is much more stable, regardless of aging, which serves as an indication of the excellent stability and durability of this promoter design. The latter observation is critical when it comes to real-life applications: refiners are interested in a stable mode of operation with little to no fluctuation of the emissions performance. A promoter such as reference- 2 would need to be continuously dosed, either via loader or as part of additional FCC catalyst to maintain average $\mathrm{CO}$ conversion activity. In contrast, a design such as catalyst $C$ will allow the refinery to reduce the overall tonnage of the promoter needed monthly. Specifically, for the case exemplified here, one could use $\sim 20 \%$ less CO promoter on a weight basis when switching from reference- 2 to catalyst $C$ without a sacrifice in $\mathrm{CO}$ activity. At the same time, the $\mathrm{NO}_{x}$ emissions would be reduced by $\sim 10-15 \%$. Most importantly, not only would the price per unit promoter $(\$ / \mathrm{kg})$ be reduced by $40 \%$ based on the Pt-loading related value, but the overall cost of $\mathrm{CO}$ promotion would be reduced as a function of lower monthly consumption. Furthermore, the improved durability of the promoter would reduce the risk of non-compliance and the amount of effort, especially in regard to monitoring as well as the actual staffing necessary to maintain promoter levels in the unit, thus simplifying the day-to-day operations for the refinery.

\section{Conclusions}

We have demonstrated that the best strategy to mitigate CO emissions from an FCC unit is to focus on the underlying chemistry rather than PGM dosing. Pt can be effectively anchored on the support by a choice of an appropriate doping package that can suppress Pt sintering. The resulting synergy between the largely retained Pt surface area and the intrinsic activity of the support allows for a substantial increase in promoter efficiency without increasing the Pt content. For instance, $\mathrm{CeO}_{2}$ is shown to greatly affect $\mathrm{CO}$ conversion as well as to have a positive effect on apparent $\mathrm{NO}_{x}$ emission, while at the same time allowing prolonged promoter durability. SrO can be employed to tune the $\mathrm{NO}_{x}$ emissions for refineries operating close to the allowed emissions limit. In turn, the correct choice of more advanced CO promoter systems allows streamlined operations and lower dosage into the FCC unit, which directly contributes to the refinery bottom line.

Author Contributions: Conceptualization, A.V. and K.C.K.; investigation, V.K. and A.D.; writingoriginal draft preparation, A.V., K.C.K. and C.C.Z.; writing-review and editing, A.V. and B.Y. All authors have read and agreed to the published version of the manuscript.

Funding: This research received no external funding.

Data Availability Statement: The data presented in this study are available on request from the corresponding author. The data are not publicly available due to BASF Corporation Confidentiality policy.

Acknowledgments: The authors would like to recognize the support and high quality of performed CO promoter testing by Angelos Lappas and Eleni Pachatouridou at the Chemical Process and Energy Resources Institute (CPERI) located in Thessaloniki, Greece.

Conflicts of Interest: The authors declare no conflict of interest.

\section{Abbreviations}

Platinum group metal (PGM), oxygen storage component (OSC), fluid catalytic cracking (FCC). 


\section{References}

1. Petroleum Sector (NAICS 324), US EPA. Available online: https://www.epa.gov/regulatory-information-sector/petroleumsector-naics-324 (accessed on 5 May 2021).

2. Air Emissions -Protecting Air Quality, Chevron Sustainability Roadmap. Available online: https://www.chevron.com/ sustainability/environment/air-emissions (accessed on 5 May 2021).

3. Chester, A.W. Chapter 6 CO combustion promoters: Past and present. Stud. Surf. Sci. Cat. 2007, 166, 67-77. [CrossRef]

4. Stockwell, D.M. Chapter 6 CO combustion promoters: Past and present. Stud. Surf. Sci. Cat. 2007, 166, 79-102. [CrossRef]

5. Gary, J.H.; Handwerk, G.E. Petroleum Refining: Technology and Economics, 4th ed.; CRC Press: New York, NY, USA, 2001; ISBN 0-8247-0482-7.

6. BASF USPTM CO Promoter. Available online: https:/ / catalysts.basf.com/products/ultra-stable-promoter-ups (accessed on 5 May 2021).

7. Lin, J.; Wang, X.; Zhang, T. Recent progress in CO oxidation over Pt-group-metal catalysts at low temperatures. Chin. J. Catal. 2016, 37, 1805-1813. [CrossRef]

8. Van Spronsen, M.A.; Frenken, J.W.M.; Groot, I.M.N. Surface science under reaction conditions: CO oxidation on Pt and Pd model catalysts. Chem. Soc. Rev. 2017, 46, 4347-4374. [CrossRef] [PubMed]

9. Jentys, A. Estimation of mean size and shape of small metal particles by EXAFS. Phys. Chem. Chem. Phys. 1999, 1, 4059-4063. [CrossRef]

10. Frenkel, A.I.; Yevick, A.; Cooper, C.; Vasic, R. Modeling the Structure and Composition of Nanoparticles by Extended X-Ray Absorption Fine-Structure Spectroscopy. Annu. Rev. Anal. Chem. 2011, 4, 23-39. [CrossRef] [PubMed]

11. APMEX Precious Metals Trading. Available online: https://www.apmex.com/platinum-price (accessed on 5 May 2021).

12. Bunluesin, T.; Putna, E.S.; Gorte, R.J. A comparison of CO oxidation on ceria-supported Pt, Pd, and Rh. Cat. Lett. 1996, 41, 1-5. [CrossRef]

13. Ferré, G.; Aouine, M.; Bosselet, F.; Burel, L.; Cadete Santos Aires, F.J.; Geantet, C.; Ntais, S.; Maurer, F.; Casapu, M.; Grunwaldt, J.-D.; et al. Exploiting the dynamic properties of Pt on ceria for low-temperature CO oxidation. Catal. Sci. Technol. 2020, 10, $3904-3917$. [CrossRef]

14. Soliman, N.K. Factors affecting CO oxidation reaction over nanosized materials: A review. J. Mat. Res. Tech. 2019, 8, 2395-2407. [CrossRef]

15. Ozawa, M.; Hattori, M.; Yamaguchi, T. Thermal stability of ceria catalyst on alumina and its surface oxygen storage capacity. J. Alloy Comp. 2008, 451, 621-623. [CrossRef]

16. Li, J.; Liu, X.; Zhan, W.; Guo, Y.; Guo, Y.; Li, G. Preparation of high oxygen storage capacity and thermally stable ceria-zirconia solid solution. Catal. Sci. Technol. 2016, 6, 897-907. [CrossRef]

17. Courtois, X.; Bion, N.; Marecot, P.; Duprez, D. Past and Present in DeNO ${ }_{x}$ Catalysis: From Molecular Modelling to Chemical Engineering. Stud. Surf. Sci. Cat. 2007, 171, 235-259.

18. Campbell, L.E.; Danzinger, R.; Guth, E.D.; Padron, S. Process for the Reaction and Absorption of Gaseous Air Pollutants, Apparatus Therefor and Method of Making the Same. US Patent 5,451,558, 19 September 1995.

19. Theis, J.; Lambert, C. The Effects of $\mathrm{CO}, \mathrm{C}_{2} \mathrm{H}_{4}$, and $\mathrm{H}_{2} \mathrm{O}$ on the $\mathrm{NO}_{\mathrm{x}}$ Storage Performance of Low Temperature $\mathrm{NO}_{\mathrm{x}}$ Adsorbers for Diesel Applications. SAE Technical Paper 2017. [CrossRef]

20. Han, L.; Cai, S.; Gao, M.; Hasegawa, J.; Wang, P.; Zhang, J.; Shi, L.; Zhang, D. Selective Catalytic Reduction of $\mathrm{NO}_{x}$ with $\mathrm{NH}_{3}$ by Using Novel Catalysts: State of the Art and Future Prospects. Chem. Rev. 2019, 119, 10916-10976. [CrossRef]

21. Wittka, T.; Holderbaum, B.; Dittmann, P.; Pischinger, S. Experimental Investigation of Combined LNT + SCR Diesel Exhaust Aftertreatment. Emiss. Contr. Sci. Technol. 2015, 1, 167-182. [CrossRef]

22. Onrubia-Calvo, J.A.; Pereda-Ayo, B.; Caravca, A.; De-La-Torre, U.; Vernoux, P.; Gonzalez-Velasco, J.R. Tailoring perovskite surface composition to design efficient lean $\mathrm{NO}_{\mathrm{x}}$ trap $\mathrm{Pd}-\mathrm{La}_{1-\mathrm{x}} \mathrm{A}_{\mathrm{x}} \mathrm{CoO}_{3} / \mathrm{Al}_{2} \mathrm{O}_{3}$-type catalysts (with $\mathrm{A}=\mathrm{Sr}$ or $\mathrm{Ba}$ ). Appl. Catal. $\mathrm{B}$ Enviromental. 2020, 266, 118628. [CrossRef]

23. Zhang, Y.; Liu, D.; Meng, M.; Jiang, Z.; Zhang, S. A Highly Active and Stable Non-Platinic Lean $\mathrm{NO}_{\mathbf{x}}$ Trap Catalyst MnO $\mathrm{C}^{-}$ $\mathrm{K}_{2} \mathrm{CO}_{3} / \mathrm{K}_{2} \mathrm{Ti}_{8} \mathrm{O}_{17}$ with Ultra-Low $\mathrm{NO}_{x}$ to $\mathrm{N}_{2} \mathrm{O}$ Selectivity. Ind. Eng. Chem. Res. 2014, 53, 8416-8425. [CrossRef]

24. Heck, R.M.; Farrauto, R.J.; Gulati, S.T. Catalytic Air Pollution Control; John Wiley and Sons: Hoboken, NJ, USA, 2009; ISBN 9781118397749. [CrossRef]

25. Borgna, A.; Le Normand, F.; Garetto, T.; Apesteguia, C.R.; Moraweck, B. Sintering of $\mathrm{Pt} / \mathrm{Al}_{2} \mathrm{O}_{3}$ reforming catalysts: EXAFS study of the behavior of metal particles under oxidizing atmosphere. Catal. Lett. 1992, 13, 175-188. [CrossRef]

26. Hansen, T.W.; DeLaRiva, A.T.; Challa, S.R.; Datye, A.K. Sintering of Catalytic Nanoparticles: Particle Migration or Ostwald Ripening? Acc. Chem. Res. 2013, 46, 1720-1730. [CrossRef]

27. Lee, J.; Ryou, Y.; Kim, J.; Chan, X.; Kim, T.J.; Kim, D.H. Influence of the Defect Concentration of Ceria on the Pt Dispersion and the CO Oxidation Activity of Pt/CeO 2 . J. Phys. Chem. C 2018, 122, 4972-4983. [CrossRef]

28. Nagai, Y.; Hirabayashi, T.; Dohmae, K.; Takagi, N.; Minami, T.; Shinjoh, H.; Matsumoto, S. Sintering inhibition mechanism of platinum supported on ceria-based oxide and Pt-oxide-support interaction. J. Catal. 2006, 242, 103-109. [CrossRef]

29. Nie, L.; Mei, D.; Xiong, H.; Peng, B.; Ren, Z.; Pereira Hernandez, X.I.; DeLaRiva, A.T.; Wang, M.; Engelhard, M.H.; Kovarik, L.; et al. Activation of surface lattice oxygen in single-atom $\mathrm{Pt} / \mathrm{CeO}_{2}$ for low-temperature $\mathrm{CO}$ oxidation. Science 2017, 358, 1419-1423. [CrossRef] [PubMed] 
30. Jones, J.; Xiong, H.; DeLaRiva, A.T.; Peterson, E.J.; Pham, H.; Challa, S.R.; Qi, G.; Oh, S.; Wiebenga, M.H.; Pereira Hernández, X.I.; et al. Thermally stable single-atom platinum-on-ceria catalysts via atom trapping. Science 2016, 353, 150-154. [CrossRef] [PubMed]

31. Yeung, C.M.Y.; Yu, K.M.K.; Fu, Q.J.; Thompsett, D.; Petch, M.I.; Tsang, S.C. Engineering Pt in Ceria for a Maximum Metal-Support Interaction in Catalysis. J. Am. Chem. Soc. 2005, 127, 18010-18011. [CrossRef] [PubMed]

32. Sala, R.; Bielaczyc, P. Accelerated Ageing Method of Three Way Catalyst Run on Test Bed with Emission Performance and Oxygen Storage Capacity Evaluation. SAE Technical. Paper 2020. [CrossRef] 